Elsevier required licence: (c) 2017. This manuscript version is made available under the CC-BY-NC-ND 4.0 license http://creativecommons.org/licenses/by-nc-nd/4.0/ 


\title{
Residential load management in an energy hub with heat pump water heater
}

\author{
Ditiro Setlhaolo ${ }^{\mathrm{a}, *}$, Sam Sichilalu ${ }^{\mathrm{b}, \mathrm{c}}$, Jiangfeng Zhang ${ }^{\mathrm{d}}$ \\ ${ }^{a}$ Faculty of Engineering and Technology, Department of Electrical and Electronic Engineering, University of \\ Botswana, Botswana. \\ ${ }^{b}$ Department of Electrical and Electronic Engineering, Faculty of Engineering, Mosi-O-Tunya University of \\ Science and Technology, Lusaka, Zambia. \\ ${ }^{c}$ School of Engineering, Department of Electrical and Electronic Engineering, University of Zambia, Zambia. \\ ${ }^{d}$ School of Electrical, Mechanical and Mechatronic Systems, University of Technology, Sydney, Australia, NSW \\ 2007.
}

\begin{abstract}
Today, as a consequence of the growing installation of efficient technologies, such as combined heat and power (CHP) as a co-generation, the integration of electricity through grid supply, Photovoltaic (PV) and energy storage systems as an integrated network is attracting a lot of attention in smart grid applications. To model the interaction among electricity and natural gas, the energy hub framework is adopted to determine a modelling procedure for such multi-carrier energy systems. This paper presents a residential energy hub model for a smart home as a modified framework of conventional energy hubs in a smart grid with consideration of heat pump water heater, coordination of sources and carbon emissions. Therefore, this study is twofold; the first part optimizes the operation of the combined CHP, Photovoltaic and storage system under time-of-use tariff. Since residential load management plays a key role in realizing household demand response programs in a smart grid, performing optimal load management in the proposed residential energy hub model is also studied in this paper. To achieve this, the optimization problem is extended by considering modelling of a heat pump water heater. It is also found out that $\mathrm{CO}_{2}$ signal could give customers an environmental motivation to shift or reduce loads during peak hours, as it would enable co-optimization of electricity consumption costs and carbon emissions reductions.

Keywords: Residential energy hub; Residential demand response; Heat pump; Optimization; time-of-Use tariff; Carbon emissions.
\end{abstract}

\footnotetext{
为

*Corresponding author. Tel.:+267 3554351; fax: +267 395-2309

Email address: setlhaolo@mopipi.ub.bw (Ditiro Setlhaolo )
} 


\section{Nomenclature}

Indices

$i \quad$ appliances index

$t \quad$ an index of the time period

$\omega \quad$ an index of weighting factors

$k \quad$ an index of flexible appliances

$j \quad$ an index of night time time loads

Sets

A a set of all household appliances

$N \quad$ the control horizon (24Hrs)

$K \quad$ a set of flexible appliances

$J \quad$ a set of night time loads

\section{Parameters}

$t_{s} \quad$ sampling time (15 mins)

$P_{i} \quad$ rated power of appliance $i(k W)$

$N_{k} \quad$ duration of appliance $k$ being on(mins)

$\rho_{t} \quad$ time-of-use electricity (TOU) price at time $t(R)$

$C \quad$ the maximum cost that the consumer is willing to pay $(R)$

$d_{k} i \quad$ the on-time start of appliance $k$

$e_{k} \quad$ the on-time end of appliance $k$

$u_{k, t}^{b l} \quad$ baseline commitment status of appliance $k$ at time $t$

power consumed by inflexible appliances $(k W)$

peat pump water heater power demand $(\mathrm{kW})$

coefficient of performance

$T_{\text {low }}, T_{u p}$

$T_{a}$

$T_{o}$

$T_{\text {in }}(t)$

$R$

lower and upper hot water temperature set points $\left({ }^{\circ} \mathrm{C}\right)$

ambient temperature $\left({ }^{\circ} \mathrm{C}\right)$

initial hot water temperature $\left({ }^{\circ} \mathrm{C}\right)$

inlet cold water temperature $\left({ }^{\circ} \mathrm{C}\right)$

$p(t) \quad$ time-of-use electricity price $(R / k W h)$

$N \quad$ total number of sampling intervals

$t_{s}$ and $k \quad$ sampling time (hour) and $k^{\text {th }}$ sampling interval respectively

$\eta_{\mathrm{CHP}_{e}} \quad$ CHP electrical efficiency

$\eta_{C H P_{e}} \quad$ CHP thermal efficiency

$D O D \quad$ depth of discharge

$\eta_{c} \quad$ battery's charging efficiency

$\eta_{d} \quad$ battery's discharging efficiency

$E_{0} \quad$ the initial state of charge of the battery at time $t$

$E^{\min } \quad$ minimum allowable battery capacity $(k W h)$

$E^{\max } \quad$ maximum allowable battery capacity in $(k W h)$

$\lambda_{c}$ the carbon emission price $(R / \mathrm{kg})$

$M_{c, t} \quad$ mass of carbon dioxide emission $(\mathrm{kg})$

$\alpha_{\text {grid }} \quad \mathrm{CO}_{2}$ emission rate of the grid $(\mathrm{kg} / \mathrm{kWh})$

$\operatorname{Rand}(R) \quad$ South African currency (1Rand $=0.080$ US D), as at 16 Mar. 2015. 


\section{Introduction}

\footnotetext{
${ }^{1}$ K. Tweed, EnergyHub plays both sides of the residential hardware debate,17 July 2012/2012 < http : //www.greentechmedia.com/articles/ >
} 
a residential energy hub with resources as combined heat and power (CHP) and electricity grid with plug-in hybrid electric vehicle (PHEV) as the charging and discharging device. A mixed integer linear programming (MILP) problem is formulated with the load classified as responsive and non-responsive appliances without consideration of carbon emissions. In [6, 7], optimal operation of residential energy hubs in smart grids is studied with consideration of carbon emissions. The disparity lies in the MILP with extensive modeling of different types of appliances in a household taking into account consumer's comfort level [6]].

General micro-grid studies have been conducted in [8-17]. However, the difference between micro-grid, energy hubs and virtual power plants has been presented in [1] and the purpose of this work is to advance research on energy hubs. However, some of the knowledge on modelling some components of energy hubs such as renewable sources, storage and loads can be borrowed from micro-grid modelling.

Research on energy hubs is very active presently and notable efforts have been made on modelling and optimization of the operation of such systems. Residential load modelling is generally dealt with under residential demand response [3, 17, 18]. The study on microgrid and hubs under demand response are carried out with consideration of carbon emissions in [19, 20]. Study on sizing and optimising CHP for residential applications is carried out in [21-26] both with and without DR. Economic evaluation of micro-CHP is carried out in [27, 28]. The study on operation of energy hubs can be conducted in two ways; economic dispatch (ED) within the hub and ED between hubs [29].

South Africa has over the years implemented residential rooftop PV systems; however grid connection of small-scale renewable electricity generation is yet to be implemented because South Africa's national regulator (NERSA) is currently in the process of developing the regulatory framework on small-scale renewable embedded generation and the guidelines on electricity reseller tariffs [30]. Some of the challenges with small-scale renewable generation grid tie include but not limited to reverse power flows and metering tariff solutions. This is the motivation for considering households with dedicated solar PV and storage systems, without feed-in to the grid.

The purpose of this paper is to formulate a practical optimal control model for ED within a hub with modelling of appliances with a heat pump and coordination of all considered resources. The heat pumps are the future energy-efficient devices and when coupled with domestic appliance scheduling can yield great success in demand side management (DSM) [31]. In this work, the problem is modelled as mixed integer nonlinear programming (MINLP) problem as compared to most literature which has presented the problem as a simplified linear problem, hence foregoing some of important sub-models and constraints of the problem and rendering the models far from reality. Therefore our work models a practical situation that gives precise predictions on optimal control settings for actual implementation. This is the contribution of this work to the general research area of residential energy hubs for smart grid applications.

The remainder of this paper is organized as follows: Sections 2 focuses on defining the problem and optimization model formulations, respectively. Section 3 provides information on the case study. While simulation results are presented and discussed in Section 4. Lastly section 5 is the conclusion. 


\section{Problem model formulation}

\section{1. proposed model schematic layout}

The optimal control model for the energy hub considered in this paper is shown in Figure 1. An energy hub is generally described relating the inputs and outputs of one unit. In this way the network is mathematically comprehensible and very adaptive for every possible combination [1, 7, 9]. In contrast to [7, 9], in this work the residential energy hub is modelled with dedicated PV, battery storage and CHP system. The layout of the considered energy hub is shown in Figure 1. In the proposed model the electrical power sources are; the micro-CHP $P_{e C H P, t}$, utility grid power $P_{g, t}$ and battery storage system $P_{b, t}^{-}$, which is in turn charged by the PV system, $P_{p v, t}$. The thermal load is satisfied by the thermal output $P_{h C H P, t}$ from the CHP. The outputs at time step $t$ are $L_{(e, t)}$ and $L_{(h, t)}$ for electrical and thermal loads respectively. The system delivers transformed electricity and gas as electrical power to electrical loads and heat to thermal loads respectively.

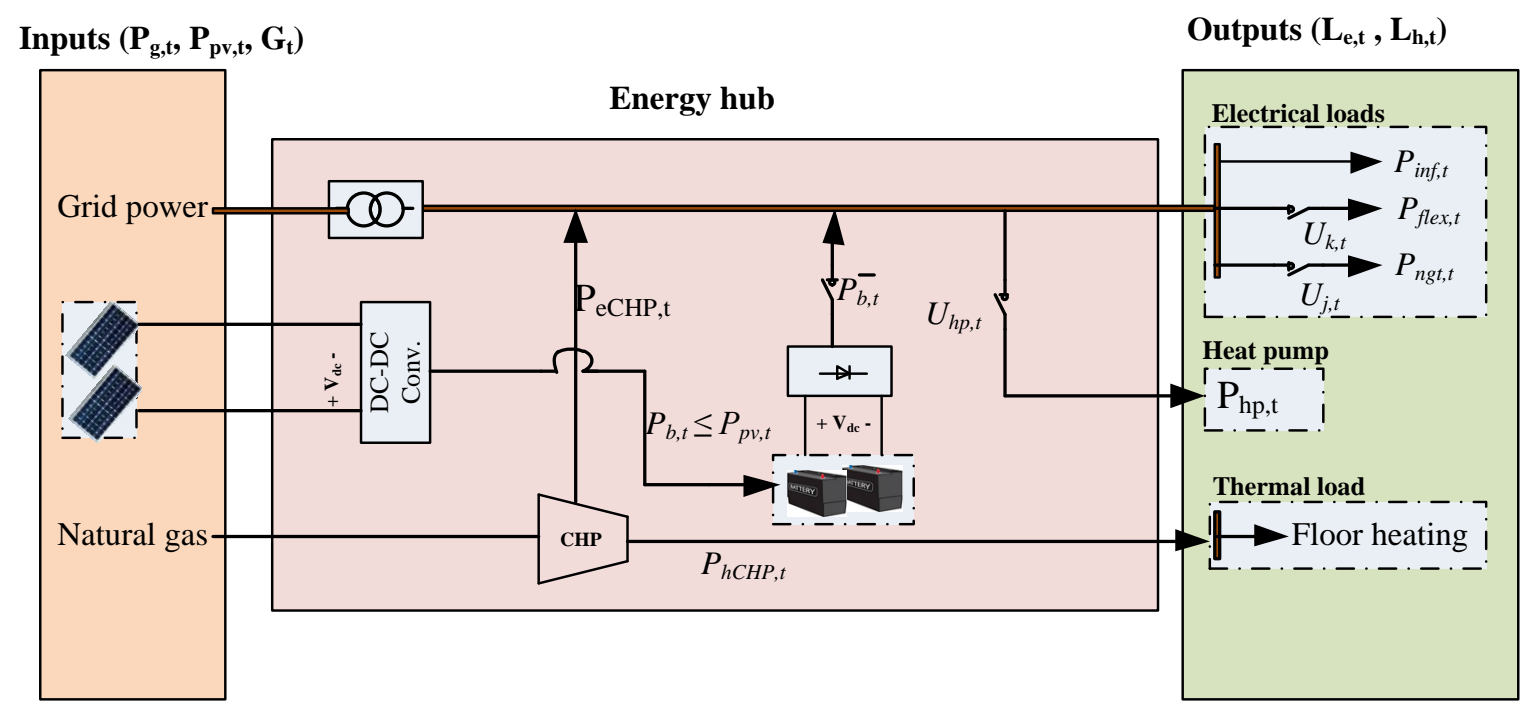

Figure 1: Schematic layout of the proposed energy hub 


\subsubsection{Battery model}

The PV-battery system is considered in this work because of their numerous benefits to both the consumer and the utility. The PV system typically has a peak generation around mid-day, which generally does not align well with on-site demand with more consumption in the evening. Storage at the PV system is used to store this energy. PV energy, like other renewable energy sources, is subject to rapid weather variations, and the resultant of this is significant grid instability. In this work, storage system is optimally charged and discharged to compensate for these fluctuations. This improves the interconnection of PV systems to the grid, and support grid stability. The battery model is presented with general battery dynamics presented by the battery's state of charge (SOC) [18, 32]. The battery energy storage system is characterized by continuous charging and discharging power, therefore $P_{b, \gamma}$ and $\bar{P}_{b, \gamma}$ are considered continuous variables at time step $\gamma$.

$$
E_{t}=E_{0}+t_{s} \sum_{\gamma=1}^{t}\left(\eta_{c} P_{b, \gamma}-\frac{\bar{P}_{b, \gamma}}{\eta_{d}}\right), 1 \leq t \leq N
$$

where $E_{t}$ is the SOC of the battery, $E_{0}$ is the initial SOC of the battery, whereas $\eta_{c} \sum_{\gamma=1}^{t} P_{b, \gamma} t_{s}$ and $\frac{1}{\eta_{d}} \sum_{\gamma=1}^{t} \bar{P}_{b, \gamma} t_{s}$ are the battery energy during the charging and discharge period, respectively.

The following constraints are applied to the battery model:

$$
E^{\min } \leq E_{t} \leq E^{\max }, t=1, \ldots, N
$$

where

$$
P_{b, t} \times \bar{P}_{b, t}=0, t=1, \ldots, N
$$

where equation (2) is the battery energy capacity limits, equation (??) is the relation between $E^{\min }$ and $E^{\max }$ through the battery's depth of discharge (DOD). equation 3 presents the exclusive operation of the battery because the battery cannot charge and discharge at the same time. This constraint also permits the battery to be in an idle mode. $N$ is the number of sampling intervals.

\subsubsection{Carbon emissions cost model}

The carbon emissions model is the carbon footprint of the consumer from the grid electricity usage offset by the injection of emission-free electricity from the $P V$ system and the CHP. The objective function is to minimize the cost of carbon emissions in a household.

$$
J_{c}=\sum_{t=1}^{N} \lambda_{C} M_{C, t}
$$


144

where $J_{c}$ is the $\mathrm{CO}_{2}$ emission cost, $\lambda_{C}$, is the emission price and $M_{C, t}$ is the mass of $\mathrm{CO}_{2}$ emission in kilogram. $\alpha_{\text {grid }}$ is the $\mathrm{CO}_{2}$ emission rate of the grid, which is $0.99 \mathrm{~kg} \mathrm{of} \mathrm{CO}_{2} / \mathrm{kWh}$ for South Africa's utility ${ }^{2}$, and is charged at $\lambda_{C}=R 0.1323 / \mathrm{kg}$, which is computed as follows;

$$
M_{C, t}=\left(\sum_{i=1}^{N} P_{g, t}+P_{b, t}-\overline{P_{b, t}}-P_{p v, t}-P_{e C H P, t}\right) t_{s} \times \alpha_{g r i d},
$$

with the assumption that the $P V$ power output is sufficient to meet the battery's requirement, that is $P_{b, t}=P_{p v, t}$, therefore, equation (5) reduces to:

$$
M_{C, t}=\left(\sum_{i=1}^{N} P_{g, t}-\overline{P_{b, t}}-P_{e C H P, t}\right) t_{s} \times \alpha_{\text {grid }} .
$$

Note that the charging of the battery is taken care of by the PV system.

\subsubsection{Combined Heat and Power model}

The CHP output model in this work is adopted from [5] as follows;

$$
P_{C H P e, t}=\eta_{C H P_{e}} G_{e},
$$

$$
P_{C H P_{h}, t}=\left(1-\eta_{C H P_{e}}\right) G_{h} .
$$

$P_{C_{C H P_{e}, t}}$ is the CHP's electrical output at time $t$ or the hub's electrical input. $\eta_{C H P_{e}}$ is the CHP's gas to electrical conversion efficiency taken as 0.4. $G_{e}$ and $G_{h}$ is the CHP gas converted to electrical power and thermal respectively, in the absence of gas burner $G_{e}=G_{h}=G_{t}$.

The CHP electrical capacity is bounded to its maximum electrical capacity;

$$
P_{C H P e, t}=C_{C H P_{e}}^{\max }
$$

where $C_{C_{H} P_{e}}^{\max }$ is the maximum electrical output capacity of the CHP.

$$
J_{C H P}=\sum_{t}^{N} \beta_{g, t} G_{t} t_{s}
$$

The main aim of objective equation (10) is to minimizes the hubs' gas input. $\beta_{g, t}$ is the price of gas at each time slot $t$ and $G_{t}$ is system's gas input. $G_{t}$ is obtained by coupling the CHP's thermal and electrical inputs to the conversion efficiency.

$$
G_{t}=\frac{P_{C H P_{e}, t}}{\eta_{C H P_{e}}}+\frac{P_{C H P_{h}, t}}{\eta_{C H P_{h}}}, \forall t
$$

\footnotetext{
${ }^{2}$ Eskom Integrated report,2014<http://http://www.integratedreport.eskom.co.za//>
} 


\subsubsection{Power balance of the energy hub}

The power flows of the system layout presented in Figure 1 is given as thus;

$$
P_{g, t}+\bar{P}_{b, t}+P_{e C H P, t}=P_{L, t}, \forall t
$$

where $P_{L, t}=P_{A, t}+U_{h p, t} \times P_{h p, t}$ is the power demanded by all appliances and the heat pump and the total power consumed by a set of all appliances $(A)$ in a household at time step $t$ is given by:

$$
\begin{aligned}
& P_{A, t}=P_{\text {inf }, t}+P_{\text {flex }, t}+P_{n g t, t}, \\
& P_{\text {inf }, t} \geq 0, P_{\text {flex }, t} \geq 0, P_{\text {ngt }, t} \geq 0,
\end{aligned}
$$

where

$$
\begin{gathered}
P_{\text {flex }, t}=\sum_{k=1}^{K} P_{k, t} u_{k, t} \\
P_{n g t, t}=\sum_{j=1}^{J} P_{j, t} u_{j, t}
\end{gathered}
$$

Household's electrical appliances are classified into three categories as $P_{t}^{\text {inf }}, P_{n g t, t}, P_{\text {flex,t }}$ denoting inflexible, night time and flexible day time loads, respectively. A household consists of these three types of loads. Flexible loads can be adjusted according to the consumer's preferences and night-time loads can be committed during the night (22:00-0:500), while inflexible appliances are non-shiftable. The household consist of a set of all appliances, $A$ and an index $i \in A$, while index of flexible appliances is $k \in K$ and night time loads are denote $j \in J . u_{k, t}$ and $u_{j, t}$ are the optimal controllable appliance status for flexible and night time loads.

The total electrical power demanded by the load in a household at time $t, L_{e, t}$, is satisfied by the battery power output $\overline{P_{b, t}}$, the power from CHP, $P_{C H P_{e}, t}$ and the grid power $\left(P_{g, t}\right)$ as in equation (12) while the output $\left(P_{p v, t}\right)$ charges the battery. The grid power supplied to the household is capped to the maximum capacity of the distribution board installed in the house as shown in equation (16).

$$
0 \leq P_{g, t} \leq P_{m}^{\max }
$$

$P_{m}^{\max }=230 \mathrm{~V} \times 60 \mathrm{~A} \times 0.75=10.35 \mathrm{~kW}$, with nominal single phase voltage and current ratings of $230 \mathrm{~V}$ and $60 \mathrm{~A}$ respectively, and an assumed power factor of 0.75 . Constraint equation (17) bounds the battery charge to the PV output.

$$
0 \leq P_{b, t} \leq P_{p v, t} .
$$




\subsubsection{Heat pump water heater model}

The heat pump model used in this paper is adopted from [14, 33], having a fixed power rating $P_{h p}(\mathrm{~kW})$. For simplicity of modelling purposes, the energy losses in the evaporator, refrigerant and compressor are accounted for by the overall coefficient of performance (COP) of other thermal components in the HPWH. A constant COP is assumed in this paper. Therefore, only energy losses as a result of hot water demand $Q_{W d, t}$ and convectional (standby) loss $Q_{\text {rad }, t}$ are considered in the model.

The standby losses, $Q_{\text {rad,t }}$, are thermal losses dispatched through the tank's casing material. These losses can be minimised through increased thermal insulation and application of low thermal conductivity materials. The per second convention loss $q_{\text {loss }}$ in $\mathrm{W} / \mathrm{m}^{2}$, according to [34], is given in equation (18),

$$
q_{\text {loss }}\left(T(t), T_{a}\right)=\frac{T(t)-T_{a}}{\frac{\Delta x}{\kappa}+\frac{1}{h}},
$$

where $\Delta x$ and $\kappa$ are the insulation thickness and thermal conductivity coefficients respectively, $h$ is the surface heat transfer coefficient of the tank and $T(t), T_{a}$ are the hot water and ambient temperature respectively. Therefore, for a given tank surface area $S_{\text {area }}$, the total standby losses are:

$$
Q_{L}\left(T(t), T_{a}\right)=q_{\text {loss }} S_{\text {area }} .
$$

The other loss is associated with the hot water demand $Q_{W d, t}$, which triggers the inlet cold water into the tank to maintain a constant volume. Therefore, $T(t)$ drops during hot water demand period because of the inlet of cold water into the tank. Losses associated with the hot water demand are given as [35, 36] in equation (20):

$$
Q_{W d, t}=c W_{D}(t)\left(T(t)-T_{i n}\right),
$$

where $c=4180 \mathrm{~J} / \mathrm{kg} /{ }^{\circ} \mathrm{C}$ is the specific heat capacity of water. $T_{\text {in }}$ is the municipal inlet water temperature whereas $W_{D}(t)$ is the hot water demand flow rate in litres/hour.

In order to satisfy the HPWH thermal output requirements, the corresponding electrical power input is [35, 38]:

$$
P_{h p}(t)=\frac{Q_{W d, t}+Q_{r a d, t}}{C O P} .
$$

The power balance is a dynamic equation. Let $Q_{H}(t)$ be the total HPWH heat output kilowatts and $L$ the water mass (tank capacity) in kilograms. Therefore, the power balance becomes a first derivative differential function given in equation (22) [37].

$$
\begin{gathered}
c L \dot{T}(t)=Q_{H}(t)-Q_{r a d, t}-Q_{W d, t}, \\
Q_{H}(t)=P_{h p} \operatorname{COPu}(t) .
\end{gathered}
$$


By substituting equation (18) to (21) into equation $(22)$, one gets

$$
\dot{T}(t)=\frac{P_{h p} \operatorname{COPu}(t)-S_{\text {area }}\left(\frac{T(t)-T_{a}}{\frac{\Delta x}{k}+\frac{1}{h}}\right)-c W_{D}(t)\left(T(t)-T_{i n}(t)\right)}{c L},
$$

denoting:

$$
\Psi(t)=\frac{S_{\text {area }}}{c L\left(\frac{\Delta x}{\kappa}+\frac{1}{h}\right)}+\frac{W_{D}(t)}{L},
$$

then equation (24) becomes:

$$
\Gamma(t)=\frac{S_{\text {area }} T_{a}}{c L\left(\frac{\Delta x}{\kappa}+\frac{1}{h}\right)}+\frac{W_{D}(t) T_{i n}(t)}{L},
$$

\subsubsection{Discrete hot water model inside the heat pump}

The water demand flow rate $W_{D}(t)$ and the inlet water, $T_{i n}(t)$, are functions of time taken from the case study. The general discrete formulation of equation $(28)$ in terms of the $k$-th hot water temperature is given in equation (29):

$$
T_{k+1}=\left(1-t_{s} \Psi_{k}\right) T_{k}+t_{s} \zeta u_{k}+t_{s} \Gamma_{k} .
$$

Then, $T_{k+1}$ at each interval can be derived as:

$$
\begin{aligned}
T_{1}= & \left(1-t_{s} \Psi_{0}\right) T_{o}+t_{s} \zeta u_{0}+t_{s} \Gamma_{0}, \\
T_{2}= & {\left[\left(1-t_{s} \Psi_{1}\right)\left(1-t_{s} \Psi_{0}\right)\right] T_{o}+t_{s} \zeta\left[\left(1-t_{s} \Psi_{1}\right) u_{0}+u_{1}\right]+\left[\left(1-t_{s} \Psi_{1}\right) t_{s} \gamma_{0}+t_{s} \Gamma_{1}\right], } \\
T_{3}= & {\left[\left(1-t_{s} \Psi_{2}\right)\left(1-t_{s} \Psi_{1}\right)\left(1-t_{s} \Psi_{0}\right)\right] T_{o}+t_{s} \zeta\left[\left(1-t_{s} \Psi_{2}\right)\left(1-t_{s} \Psi_{1}\right) u_{0}+\left(1-t_{s} \Psi_{2}\right) u_{1}+u_{2}\right] } \\
& +\left[\left(1-t_{s} \Psi_{2}\right)\left(1-t_{s} \Psi_{1}\right) t_{s} \gamma_{0}+\left(1-t_{s} \Psi_{2}\right) t_{s} \Gamma_{1}+t_{s} \gamma_{2}\right], \\
& \vdots \\
T_{k+1}= & T_{o} \prod_{j=0}^{k}\left(1-t_{s} \Psi_{j}\right)+t_{s} \zeta \sum_{j=0}^{k} u_{j} \prod_{i=j+1}^{k}\left(1-t_{s} \Psi_{i}\right)+\sum_{j=0}^{k} t_{s} \Gamma_{j} \prod_{i=j+1}^{k}\left(1-t_{s} \Psi_{i}\right),
\end{aligned}
$$

where; $T_{o}$ and $T_{k}$ are the initial and $k$-th water temperatures inside the tank respectively. $t_{s}$ is the sampling time, whereas $u_{k}$ is the $k$-th switch status, which is either 1 or $0 . \Psi_{j}$ and $\gamma_{j}$ are functions of equation (25) and equation (27) respectively and $\zeta$ represents a constant given equation (26). The acceptable hot water temperature set points are given by inequality (31):

$$
T_{\text {low }} \leq T_{k} \leq T_{u p}
$$

where, $T_{l o w}$ and $T_{u p}$ are the lower and upper desired temperatures respectively. 


\subsubsection{Appliance operational model}

Given the predetermined parameters of the controllable appliances; $d_{k}, e_{k}$ and $N_{k}$, as the beginning and end of time to which each flexible appliance is to be scheduled, and duration required to finish the normal operation of each controllable appliance, the following; equation (32) holds.

$$
\sum_{t=d_{k}}^{e_{k}} u_{k, t}=N_{k}, \forall k
$$

where

$$
\begin{gathered}
N_{k} \leq\left(e_{k}-d_{k}\right) . \\
\sum_{t=d_{k}}^{e_{k}} u_{k, t} \cdot u_{k,(t+1)} \cdot u_{k,(t+2)} \cdots u_{k,\left(t+\left(N_{k}-1\right)\right)}=1, t=1, \ldots, N . \\
u_{2, t}-u_{6, t}-u_{7, t}=0 \\
d_{6}+N_{6} \leq d_{7+1} . \\
0 \leq P_{k, t} \leq P_{k}^{\max },
\end{gathered}
$$

where nonlinear constraint equation (34) models the non-interruptible operation of appliances. Equality (35) and inequality (36) are coordination constraints. equation (35) coordinates lighting with the appliances used in their respective rooms, using the the laundry room as a reference. The time the laundry lights are off is when neither washing machine nor drier is on. equation (36)ensures that, for example, the dryer follows the washing machine. The numerical indices in equation (35) and inequality (36) correspond to appliance index as provided in Table 1 . The laundry room lights has index $i=2$, washing machine, $i=6$, and dryer has index $i=6$. Inequality (37) is the appliance power consumption limit.

$$
t_{s} \rho_{t} \sum_{t=1}^{T}\left(P_{i n f, t}+\sum_{j=1}^{J} P_{j, t} u_{j, t}^{n g t}+\sum_{k=1}^{K} P_{k, t} u_{k, t}+u_{i, t} P_{h p, t}\right) \leq C .
$$

This constraint models the maximum cost that the household is willing to incur within the control horizon. The parameter $C$ is obtained from the consumer's bill and provided in the case study. 


$$
J_{e}=t_{s} \rho_{t} \sum_{t=1}^{T}\left(P_{\text {inf }, t}+\sum_{j=1}^{J} P_{j, t} u_{j, t}+\sum_{k=1}^{K} P_{k, t} u_{k, t}^{\text {flex }}\right) .
$$

where typically

$$
u_{k, t}^{f l e x}= \begin{cases}1, & \text { when day flexible appliance } k \text { is on at time } t \\ 0, & \text { when day flexible appliance } k \text { is off at time } t\end{cases}
$$

It is assumed that the types of appliances that cause most inconvenience are flexible appliances. The baseline $u_{(k, t)}^{b l}$; the baseline appliance average switching status is obtained from the measured data.

\subsection{Objective function}

The energy hub operational optimization model under consideration consists of electrical power from the grid, gas input, carbon emissions and inconvenience costs that need to be minimized. In order to obtain a parento optimum operational scheme in equation (40), a weighting method is employed to integrate the sub-objectives into one. The advantage of this approach is that the consumer has an option to choose the objective to use to control their consumption. The household seeks to minimize the following combined cost function. Where $\omega$ is the index of weighting factors and $\omega_{i}$, represents the weighting attached to these sub-objectives according to the consumer's preference, and $\sum_{\omega=1}^{4} w_{\omega}=1$.

$$
\min J=\omega_{1} J_{e}+\omega_{2} J_{C H P}+\omega_{3} J_{C}+\omega_{4} J_{I}
$$

The first term minimizes the hubs' grid's electrical energy input,second sub-objective minimises the cost of using CHP, the third term is the carbon emissions cost while the fourth is the inconvenience cost brought by appliance optimal schedule against the baseline. The formulated model is MINLP optimal control problem with control variables $u_{k, t}, u_{j, t}, u_{h p, t}, P_{b, t}$, $\overline{P_{b, t}}$, and $P_{g, t}, G_{t}, P_{e C H P, t}, P_{h C H P, t}$. The objective function equation 40 is subjected to the presented constraints.

\subsection{Optimization solution methodology}

The MINLP optimization problem equation (40) is solved with an optimization solver, SCIP, available in the Matlab interface OPTI toolbox. The simulation study is performed for a 24 hour control horizon, at a sampling time $t_{s}$ of 15 minutes. SCIP is currently one of the fastest non-commercial solvers for MIP and MINLP. It is also a framework for constraint integer programming and branch-cut-and-price ${ }^{34}$. It uses Interior Point Optimizer (IPOPT)

\footnotetext{
${ }^{3}$ SCIP: Solving Constraint Integer Programs.< http://scip.zib.de/>.

${ }^{4}$ T.Berthold, et al., Solving mixed integer linear and nonlinear problems using the SCIP Optimization Suite, ZIB-Report 12-27 (July 2012), Takustrae 7 D-14195 Berlin-Dahlem Germany.<file://C:/Users/User/Downloads/ZR-12-27\%20(1).pdf>
} 
and SoPlex as nonlinear and integer algorithms. SoPlex is an advanced implementation of the revised simplex algorithm for solving linear programs. It features preprocessing, exploits sparsity, and provides primal and dual solving routines. It is the default LP solver in SCIP. IPOPT is an open-source solver for large-scale nonlinear programming. IPOPT implements a primal-dual interior point method and uses line searches based on filter methods 6.7 . The solver offers solutions to problems of the form:

$$
\min f(x), \text { s.t., }\left\{\begin{array}{l}
A x \leq b, A_{e q} x=b_{e q}(\text { linear constraints }) \\
c(x) \leq d, c_{e q}(x)=d_{e q}(\text { nonlinear constraints }) \\
L b \leq x \leq U b(\text { variable bounds }) \\
x_{i} \in \mathbb{Z}(\text { integer decision variables }) \\
\left.x_{j} \in\{0,1\}, i \neq j \text { (binary decision variables }\right)
\end{array}\right.
$$

The measured results are compared with simulation results to demonstrate the effectiveness of the algorithm.

\section{Case study}

A typical apartment in South Africa has been used as a case study with appliances shown in Table 1. The household has a dedicated PV and battery system and a CHP.

\subsection{Tariff}

The tariff used is based on South Africa's TOU Homeflex 1 tariff structure for residential consumers. The Homeflex 1 tariff has five charge component ${ }^{3}$ as service charge, network charge, environmental levy, peak charge and off-peak charges. We model these into fixed and variable charges as follows:

$$
\rho_{t}=F_{C}+V_{C},
$$

where $F_{C}$ is a fixed charge and consist of service charge, network charge and environmental levy, while $V_{C}$ are peak and off-peak energy charges.

$$
F_{C}=R(2.96+3.68+2.00) / 100 \text {, }
$$

and

$$
V_{C}= \begin{cases}R 1.7487, & \text { peak time }, t \in[07: 00,10: 00),[18: 00,20: 00) \\ R 0.5510, & \text { off-peak time, } t \in[00: 00,07: 00),[10: 00,18: 00],[20: 00,00: 00]\end{cases}
$$

\subsection{Appliance data}

Appliance maximum rated power is specified by the appliance manufacturers and can be obtained from the appliances. One month's weekday data on appliance usage in the household under study were collected. Table 1 shows flexible, inflexible and night-time loads considered for this work. Table 1 also shows the measured maximum run-time, $N_{k}$, of appliance $k$.

\footnotetext{
${ }^{7}$ Opti Toolbox solvers. <http://www.i2c2.aut.ac.nz/Wiki/OPTI/index.php/Solvers> Date accessed 11.12.2016

${ }^{3}$ Eskom tariffs and charges $2011 / 2012<$ http : //eskom.com $>$
} 
Table 1: Appliances data

\begin{tabular}{|l|l|c|l|}
\hline Index $(i)$ & Appliances & Rated Power $P_{i}(k W)$ & Duration $N_{i}($ hrs/day $)$ \\
\hline & Flexible & & \\
1 & Kitchen lights & 0.11 & As kitchen appliances \\
2 & Laundry room lights & 0.11 & As laundry appliances \\
3 & Microwave & 1.5 & 1 \\
4 & Stove & 2.2 & 2 \\
5 & EWH & 2.0 & 5 \\
6 & Washing machine & 2.4 & 2 \\
7 & Clothes dryer/spin & 2.0 & 1 \\
8 & Vacuum cleaner & 0.8 & 1 \\
9 & DVD player & 0.025 & 3 \\
& Inflexible & & \\
10 & TV room lights & 0.11 & As Tv \\
11 & Refrigerator & 0.4 & 3 \\
12 & Television & 0.25 & 3 \\
13 & Decoder & 0.07 & 3 \\
& Night loads & & \\
14 & Breadmaker & 1.5 & 3 \\
15 & Dishwasher & 1.5 & 3 \\
\hline
\end{tabular}

The the maximum budget $(\mathrm{C})$ that the household is willing to incur in the study horizon is (R) 25. This data is obtained from the bill of the consumer.

\subsection{Photovoltaics array and battery data}

The household is assumed to have a battery bank with data provided in Table 2 and the data for $P V$ is shown in Figure 2, this data is adopted from [15]. The battery capacity is an assumed value of $10 \mathrm{kWh}$. The minimum discharge capacity of $50 \%$ has been shown to sustain the lifespan of the battery [16]. 


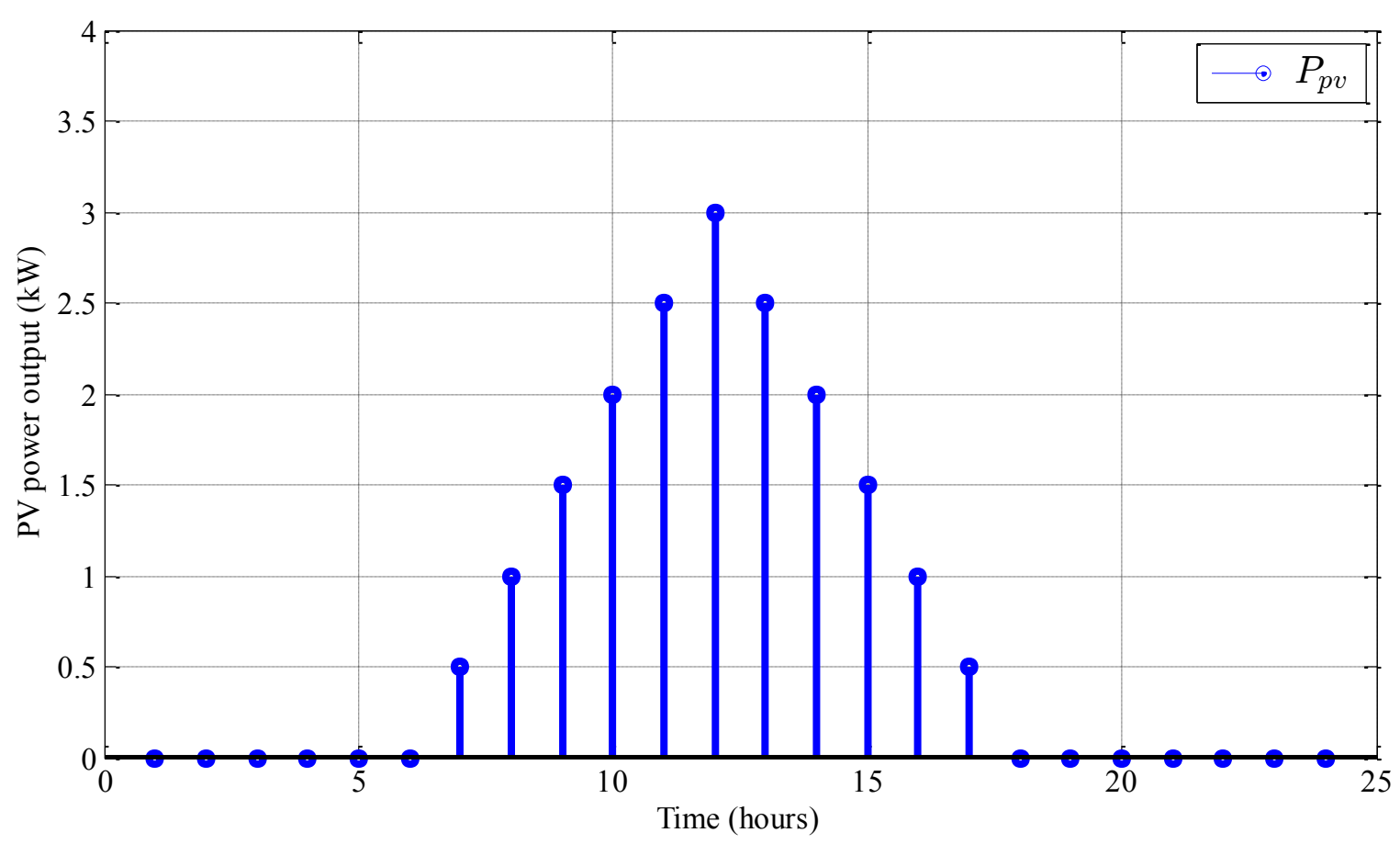

Figure 2: PV power output

Table 2: Battery data

\begin{tabular}{|l|l|}
\hline Battery capacity & $10 \mathrm{kWh}$ \\
\hline$\eta_{c}$ & $75 \%$ \\
\hline$\eta_{d}$ & $100 \%$ \\
\hline DOD & $50 \%$ \\
\hline
\end{tabular}

\subsubsection{Heat pump water heater parameters}

The HPWH considered in this paper is a Quantum solar heat pump! air source tankwrapped heat exchanger (condenser) and its parameters are shown in Table 3 .

Table 3: Heat pump parameters

\begin{tabular}{|c|c|c|c|c|c|c|c|c|}
\hline $\begin{array}{l}\text { Power } \\
(k W)\end{array}$ & input & COP & $\begin{array}{c}\text { Storage capacity } \\
(l)\end{array}$ & Compressor $(c c)$ & Tank $(\mathrm{h} / \emptyset)(m)$ & $\Delta x(m)$ & $\kappa(W / m . K)$ & $h\left(W / m^{2} K\right)$ \\
\hline 7 & & 3.8 & 270 & 39.0 & $1.41 \times 0.66$ & 0.035 & 0.055 & 6.3 \\
\hline
\end{tabular}

The preferred hot water temperature is set to $50^{\circ} \mathrm{C} \leq T_{k} \leq 60^{\circ} \mathrm{C}$; the average country ambient temperature of $T_{a}=25^{\circ} \mathrm{C}$ is used. The initial water temperature in the tank is set to $T_{o}=52^{\circ} \mathrm{C}$. However, the above desirable temperature varies from one individual to another. The hot water demand and inlet temperatures extrapolated from [41]

\footnotetext{
${ }^{1}$ www.quantumecohotwater.com.au
} 


\section{Simulation results and discussion}

This section of the manuscript present the results obtained from the simulation with the weighting factors as $\mathrm{w} 1=0.3 ; \mathrm{w} 2=0.2 ; \mathrm{w} 3=0.2 ; \mathrm{w} 4=0.3$.

In Figure 3, the optimal power flows are shown represented as; total electrical load consumed in the household $P_{L}$, grid power $P_{g}$, battery discharge power $\bar{P}_{b}$ and the CHP electrical output power $P_{\text {eCHP. }}$. The load power is at its peak morning at 08:00-09:00 at a load of 5.84kW and an evening peak of $6.85 \mathrm{~kW}$ at $18: 00$. During the morning peak the load is satisfied by the grid power $P_{g}=2.07 \mathrm{~kW}$ and the battery $\bar{P}_{b}=3.58 \mathrm{~kW}$ while the CHP power is zero. At evening peak the load is also satisfied by both $P_{g}=2.07 \mathrm{~kW}$ and $\bar{P}_{b}=4.7832 \mathrm{~kW}$ while $P_{e} C H P=0 \mathrm{~kW}$. However CHP supplies maximum power at $t=22: 00$ of $1.944 \mathrm{~kW}$. It is observed that the CHP supplies electrical power at all other times except at peak times because at that time it is more cheaper to use the battery than CHP. During off-peak times the load is met by both CHP and the grid, typically at $t=11: 00 ; \bar{P}_{b}=0 \mathrm{~kW}, P_{g}=2.07 \mathrm{~kW}$ and $P_{e} C H P=1.3722 \mathrm{~kW}$ which both satisfy a load of $P_{L}=3.4422 \mathrm{~kW}$. At $t=23: 00$; $P_{L}=3.6142 \mathrm{~kW}, \bar{P}_{b}=0 \mathrm{~kW}, P_{e} C H P=1.5442 \mathrm{~kW}$ and $P_{g}=2.07 \mathrm{~kW}$.

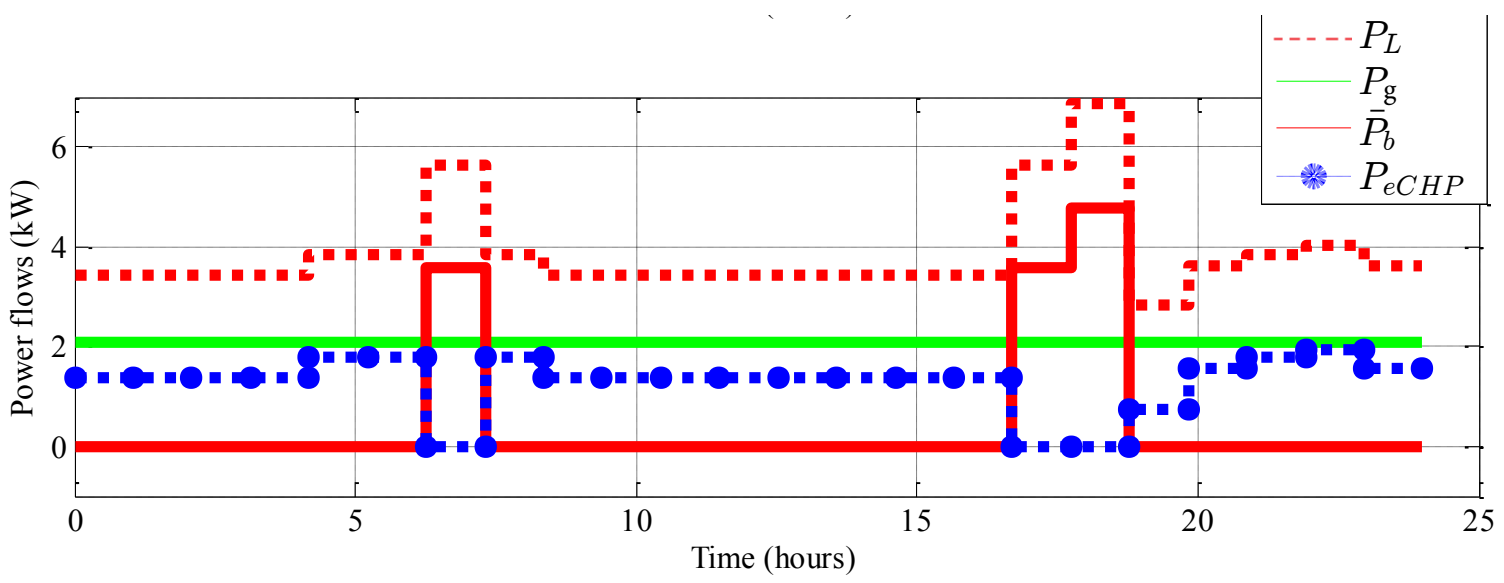

Figure 3: Optimal power flows from the hub and the loads

Figure 3 above shows that the grid power stays almost relatively constant, with a very small variation. This solution suggests that it is more expensive to have CHP during peak times. It also shows that the consumer, with a number of sources can utilize less power from the grid and this could provide a great benefit to the grid in achieving less power consumption from the grid for stability. Figure 3 power flow simulations do satisfy the power balance equation equation (12) where it shows that the load $P_{L}$ is satisfied by all the three supply sources at any given time. At peak times power drawn from the grid is reduced by $64.55 \%$ and $69.79 \%$, respectively for morning and evening peaks. During off-peak times it reduced by a maximum of $60.15 \%$. This information could be very much useful to the utilities.

The use of renewable source's saves the $\mathrm{CO}_{2}$ emissions by over $80 \%$ in the day considered. Figure 4 shows baseline and optimal emissions scatter plots. 


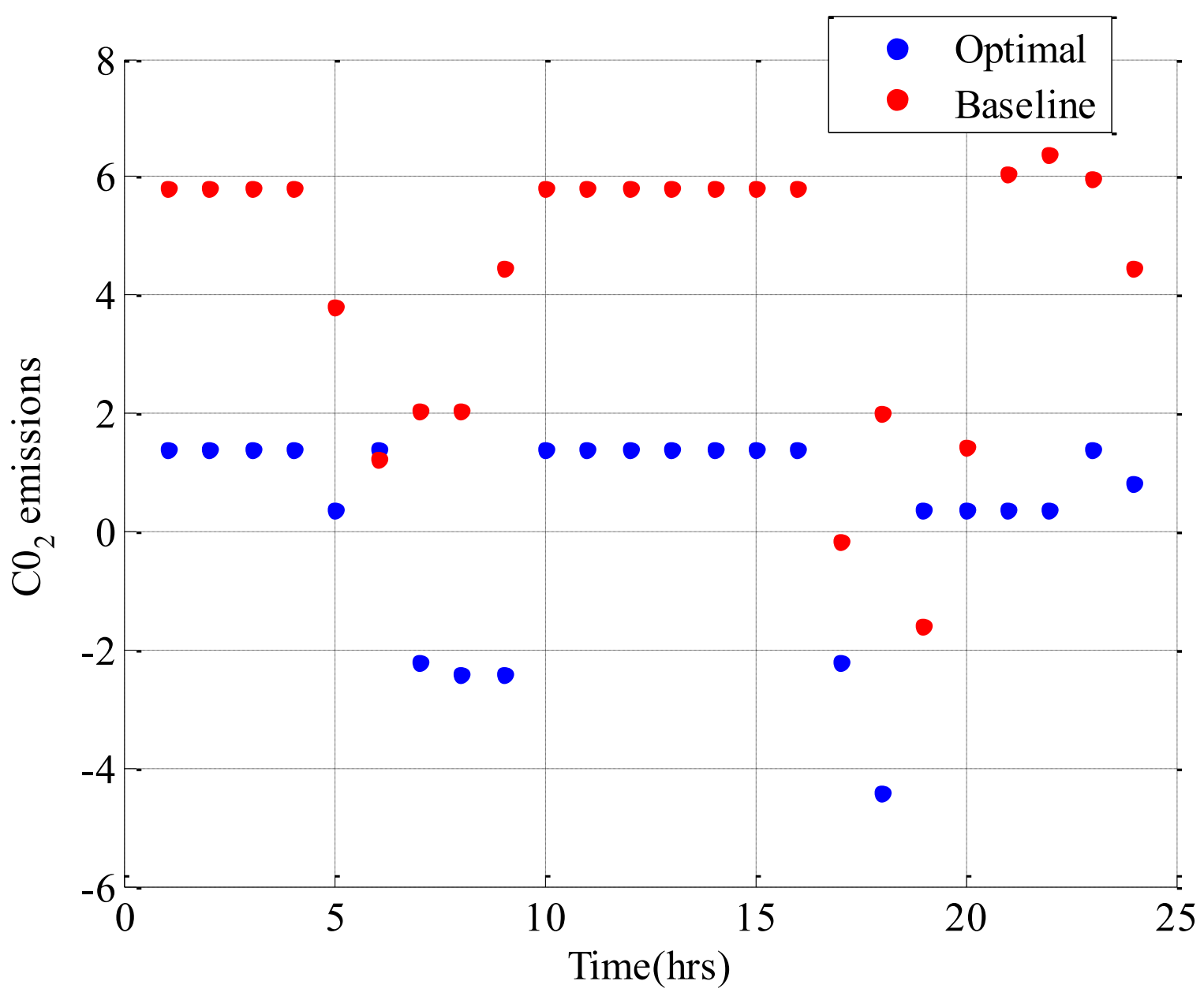

Figure 4: Baseline \& optimal $\mathrm{CO}_{2}$ emissions

Though, it is debatable whether CHP contributes to $\mathrm{CO}_{2}$ or not. In this paper, it has been assumed that the CHP fuel does not produce emissions, the though energy hub is charged. It is still an area that needs further study because [39] suggests that it is not always that CHP would bring $\mathrm{CO}_{2}$ savings. In their work, they discuss the impact of some major variables on the $\mathrm{CO}_{2}$ emission reduction capacity of co-generation. They consider two sets of variables: the characteristics of the CHP process and the composition of the electricity generation sector that are found to have an impact on $\mathrm{CO}_{2}$ reduction. However, in [40], they found out that CHP contributes greatly in $\mathrm{CO}_{2}$ mitigation. Therefore, this area needs further investigation.

Figure 5 shows the heat pump load switching schedule. From 00:00 to 05:00 the heat pump switches on to heat the water before morning peak. The optimal control avoids scheduling it during morning peak, though it bring it in to maintain the temperatures within desirable range as shown in Figure 6. 


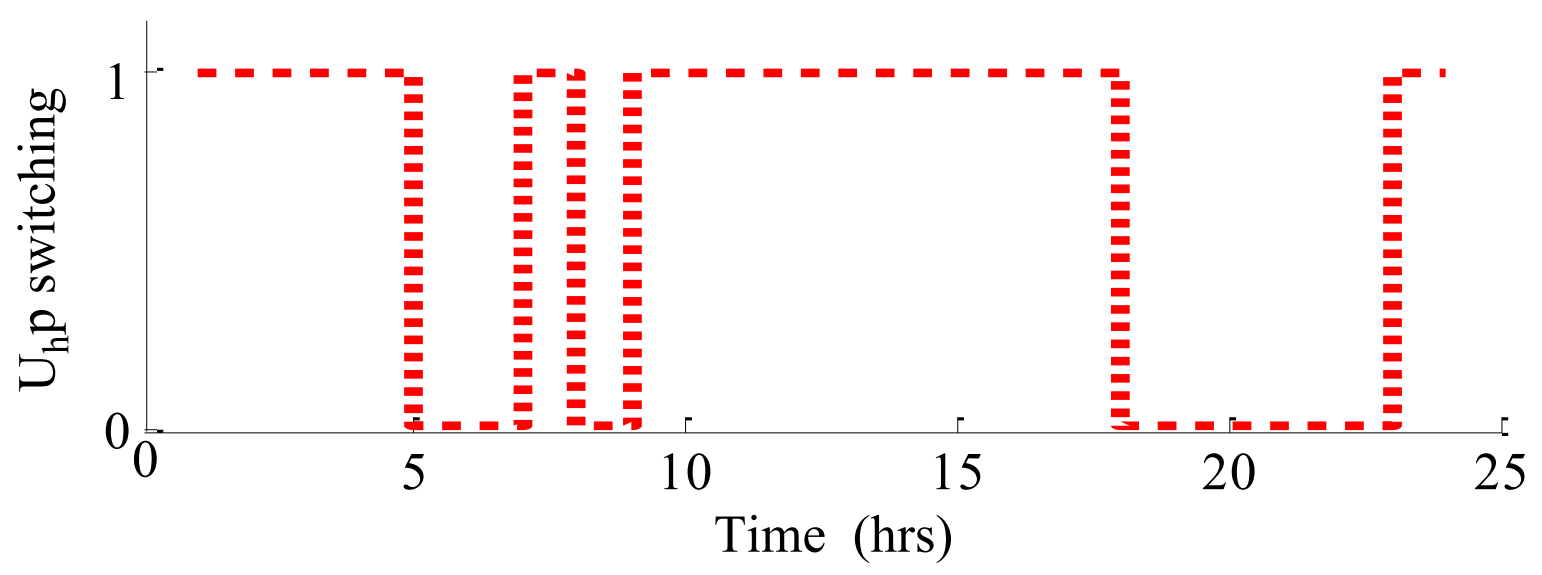

Figure 5: The switching frequency of the heat pump

. . TOU period which subsequently lowers the energy bill.

The optimal temperature of the hot water supplied by heat pump is shown in Figure 6 . The hot water temperature, $T_{k}$, rises from the initial $T_{o}=52{ }^{\circ} \mathrm{C}$ to $57^{\circ} \mathrm{C}$ at $04: 00$. Thereafter, at 05:00 the temperature start dropping due to hot water demand. $T_{k}$ lowers to $51^{\circ} \mathrm{C}$ at 09:00 due to high water demand, however, the optimal control switches on (as shown in Figure 5) the heat pump and temperatures rises to $59^{\circ} \mathrm{C}$ at 17:00. The hot water temperatures is kept within customer desirable temperatures throughout the day at the same time benefiting from the reduced energy bill.

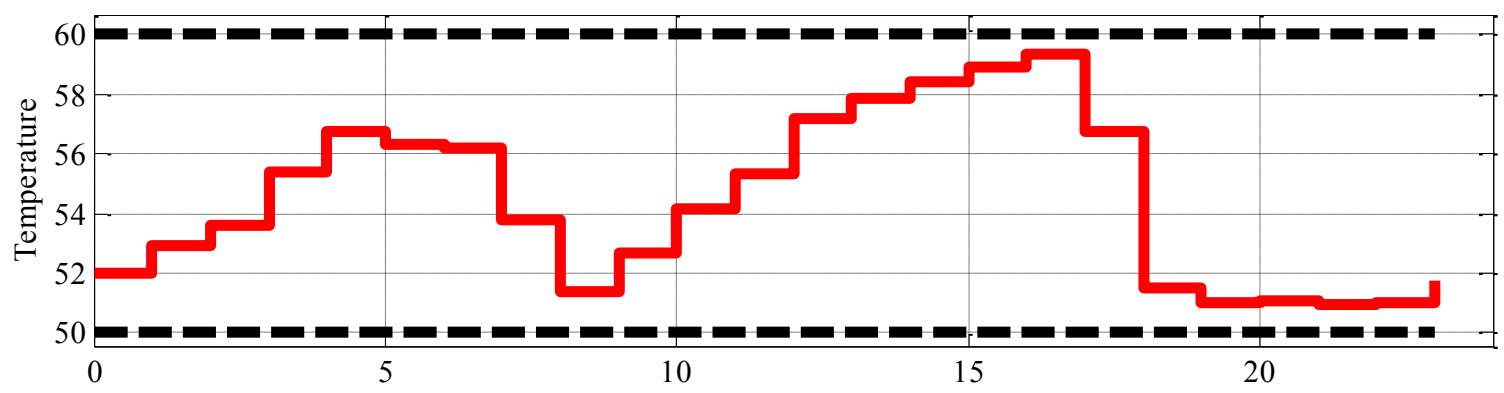

Figure 6: Optimal hot water temperature inside the heat pump water heater tank

The optimal control is meeting the customer's constraints by providing the desirable hot water temperature, at the same time saving the energy cost.

The battery's SOC is shown Figure 7. The SOC is constant from midnight to 06:00 in the morning till sunrise. There is no PV production during the night, however, as the sun 
irradiance begun the SOC is shown to increase from $5 \mathrm{kWh}$ to $10 \mathrm{kWh}$ at 09:00. The battery is fully charged and only at 18:00 during evening peak the battery supplements ( as shown in (Figure 3) the grid power and CHP to meet the loads.

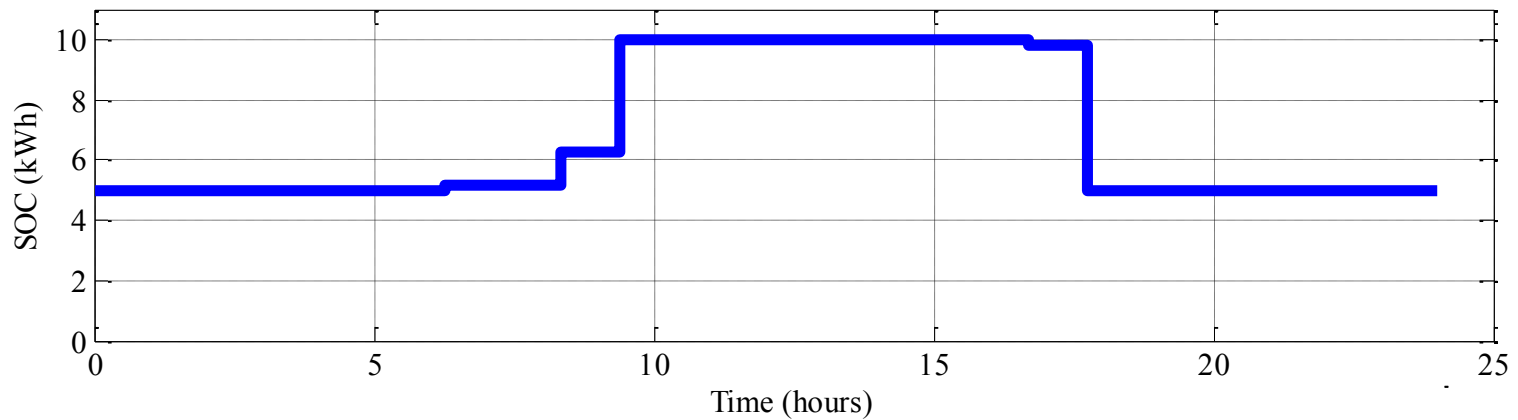

Figure 7: The battery status of charge

Therefore, the SOC drops to 5kWh after 18:00 and the battery is not charged again due to the absence of the sun.

Figure 8 presents simulation of the coupling of CHP gas parameters the $G_{t}$ gas input with $G_{e}$ and $G_{h}$ as gas for conversion to electrical and thermal loads respectively. The upper two sub-plots; the first one is the gas used for electrical while the second one is for conversion into thermal. The thermal loads consumes a constant amount of gas input at 2.778 while gas for electrical loads varies for example at morning and evening peaks gas converted to electrical power is zero and this is in agreement with the load flow relations in Figure 3 where during peak times the CHP does not supply the electrical load. 

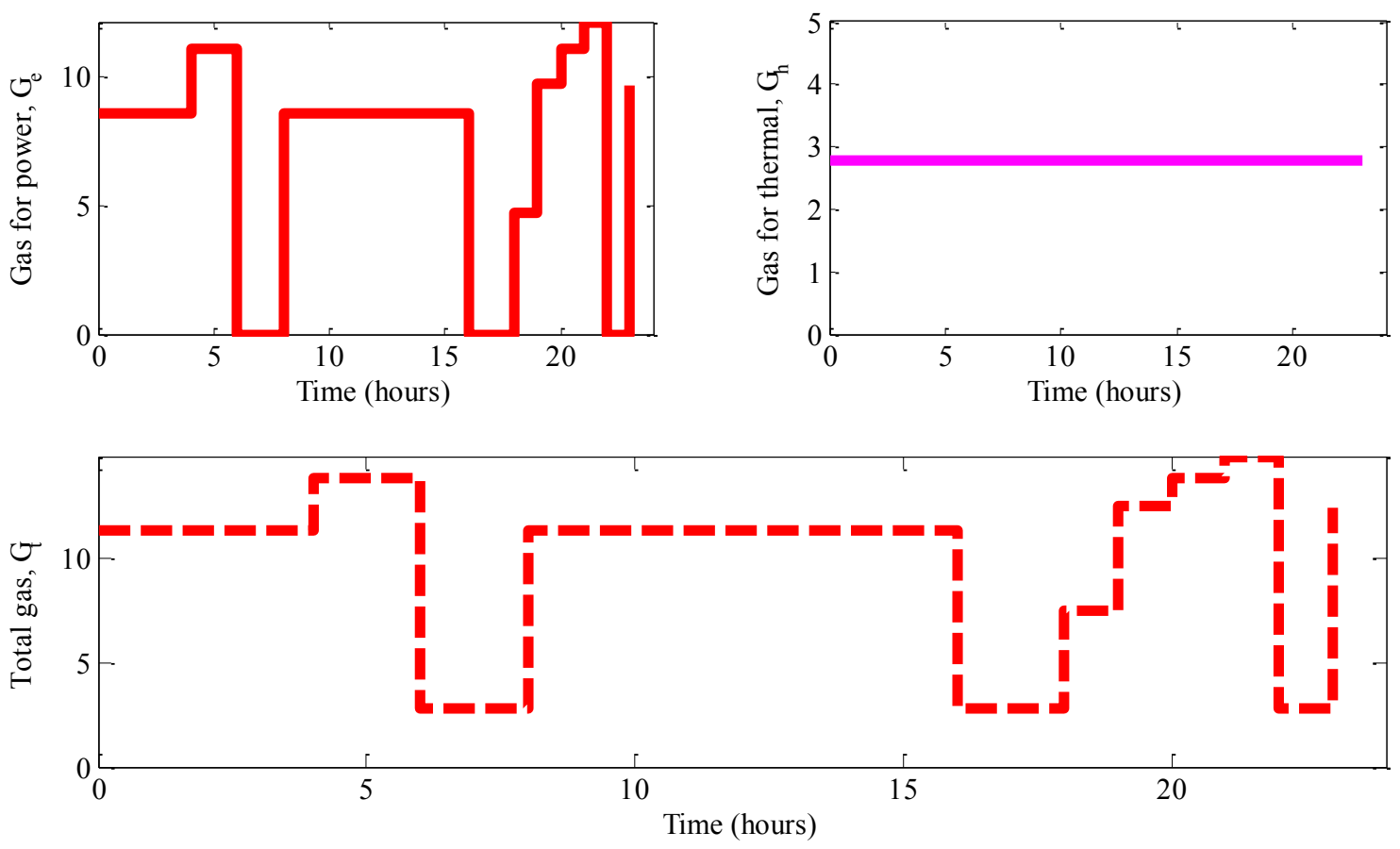

Figure 8: Gas coupling

The gas consumption is at its maximum value of 14.9292 at $\mathrm{t}=22: 00$. It is at this time where we have seen above in the load flows that CHP supplies maximum power to the load.

Figure 9 shows the cost components of: baseline(BL), optimal costs of all appliances and heat pump (LS), LS with battery discharging (LSBD), LSBD with CHP (LSBDECHP) and carbon cost $\left(\mathrm{CO}_{2}\right)$ that the baseline cost of supplying all appliances and a heat pump is R111.57 and this cost is brought down by $47 \%$ due to optimal scheduling of appliances and the heat pump. It must be noted that it is assumed that the HP is switched on most hours of the day before the applying the strategy. 


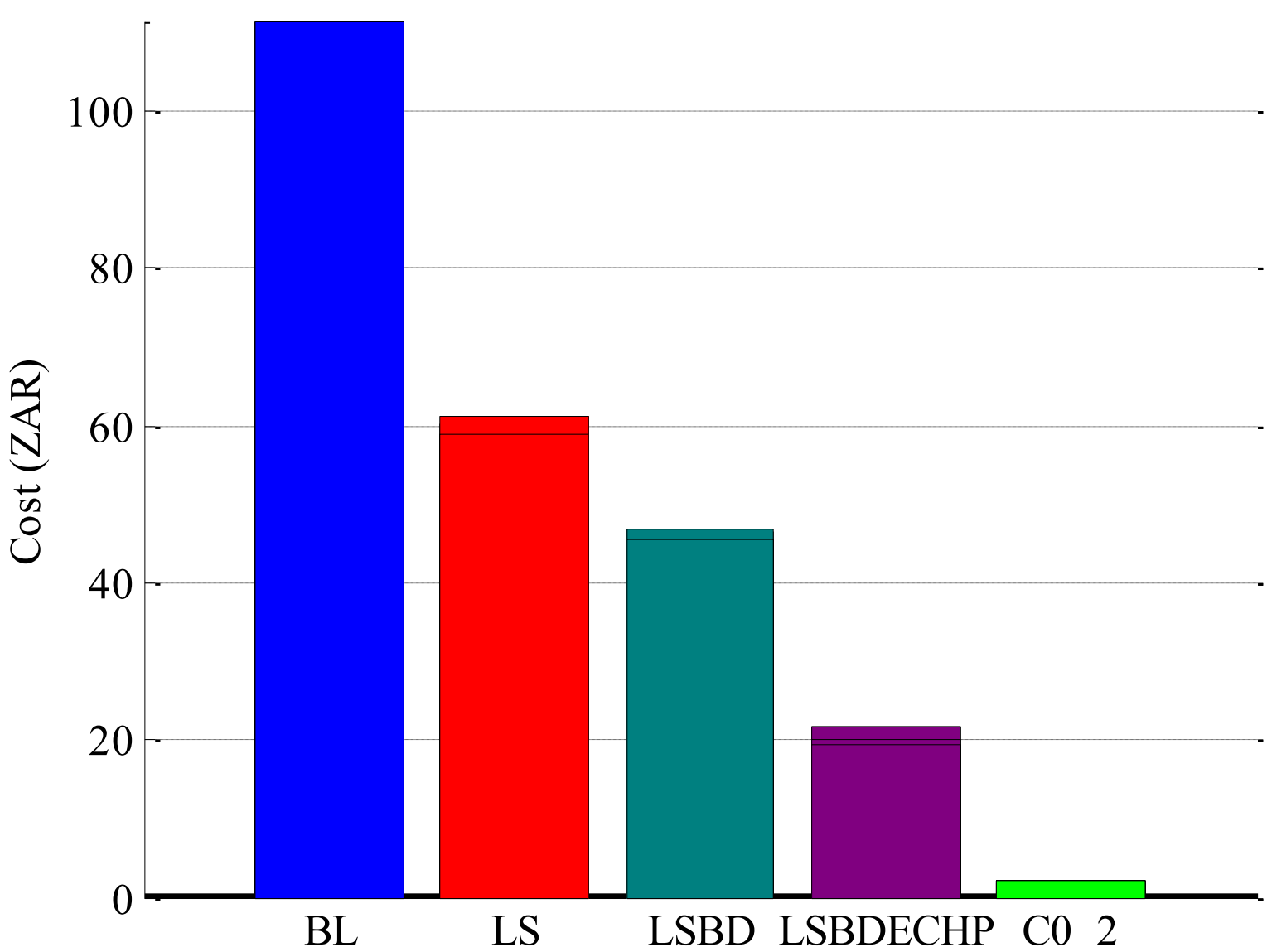

Figure 9: Cost comparison

The cost is further brought down by $12.15 \%$ due to the use of PV/Battery system while on the other hand $23 \%$ cost savings is realised due to the CHP. These results show that the optimal scheduling of appliances brings a significant contribution to the household energy cost reduction followed by the CHP while the PV/Battery system is the least. It is to be noted that the cost saving due to appliance shifting is affected by the disparity between the peak and off-peak price, which in this case is $30 \%$.

\section{Conclusion}

An optimal control problem has been formulated to model the interaction among electricity and natural gas, the energy hub framework is adopted to determine a modelling procedure for such multi-carrier energy systems for grid connected residential with a CHP, PV and battery storage system under DR. It has been shown that use of energy carrier can help in modelling a residential with several interconnected sources and loads. It has been shown by simulation that the residential with can have different cost savings due to each supply component. The grid power has been dropped by a minimum of $60 \%$ while the $\mathrm{CO}_{2}$ emissions have 
been reduced by over $80 \%$ with the assumption that the CHP contributes to the reduction of emissions.

The benefit of the model could afford economic benefit to the residential consumers as has been seen in this case that the cost of power from the grid has been reduced by over $70 \%$. The power consumption from the grid has been tremendously reduced and this is crucial to utilities. The electricity maximum cost savings realised from this arrangement is $95 \%$. The carbon emissions are also are also reduced in this set up. Economic analysis to show the time of break even for the consumer on when they would start making returns from their capital incurred on the actual system is a further research that is currently ongoing.

[1] R. Bhler, Integration of renewable energy sources using microgrids, virtual power plants and the energy hub approach, Semester thesis, Swiss Federal Institute of Technology, Zurich (2010).

[2] Y. Huang, H. Tian, and L. Wang, Demand response for home energy management system, International Journal of Electrical Power \& Energy Systems 73 (2015): 448-455.

[3] M. C. Bozchalui, S. A. Hashmi, H. Hassen, C. Caizares, and K. Bhattacharya, Optimal operation of residential energy hubs in smart grids, Smart Grid, IEEE Transactions on 3.4 (2012): 1755-1766.

[4] M. Rayati, A. Sheikhi, and A. M. Ranjbar, Optimising operational cost of a smart energy hub, the reinforcement learning approach, International Journal of Parallel, Emergent and Distributed Systems ahead-of-print (2014): 1-17.

[5] M. Rastegar, M. Fotuhi-Firuzabad, and M. Lehtonen, Home load management in a residential energy hub, Electric Power Systems Research 119 (2015): 322-328.

[6] A. Parisio, C. Del Vecchio, and G. Velotto, Robust Optimization of operations in energy hub, Decision and Control and European Control Conference (CDC-ECC), 2011 50th IEEE Conference on. IEEE, 2011.

[7] M. Moeini-Aghtaie, P. Dehghanian, M. Fotuhi-Firuzabad, and A. Abbaspour, Multiagent genetic algorithm: An online probabilistic view on economic dispatch of energy hubs constrained by wind availability, Sustainable Energy, IEEE Transactions on 5.2 (2014): 699-708.

[8] P. O. Kriett, and M. Salani, Optimal control of a residential microgrid, Energy 42.1 (2012): 321-330.

[9] S. R. Sivarasu, E. C. Sekaran, and P. Karthik, Development of renewable energy based microgrid project implementations for residential consumers in India: Scope, challenges and possibilities, Renewable and Sustainable Energy Reviews 50 (2015): 256269. 
[10] C. Wouters, E. S. Fraga, and A. M. James, An energy integrated, multi-microgrid, MILP (mixed-integer linear programming) approach for residential distributed energy system planning?A South Australian case-study, Energy 85 (2015): 30-44.

[11] F. A. Mohamed, and H. N. Koivo, Online management genetic algorithms of microgrid for residential application, Energy Conversion and Management 64 (2012): 562-568.

[12] E. Kuznetsova, Elizaveta, C. Ruiz, Y. F. Li, and E. Zio, Analysis of robust optimization for decentralized microgrid energy management under uncertainty, International Journal of Electrical Power \& Energy Systems 64 (2015): 815-832.

[13] M. Mazidi, A. Zakariazadeh, S. Jadid, and P. Siano, Integrated scheduling of renewable generation and demand response programs in a microgrid, Energy Conversion and Management 86 (2014): 1118-1127.

[14] S. M. Sichilalu, and Xiaohua Xia, Optimal energy control of grid tied PV-diesel-battery hybrid system powering heat pump water heater, Solar Energy 115 (2015): 243-254.

[15] E. Kuznetsova, Y. F. Li, C. Ruiz, and E. Zio, An integrated framework of agent-based modelling and robust optimization for microgrid energy management, Applied Energy 129 (2014): 70-88.

[16] G. Comodi, et al, Multi-apartment residential microgrid with electrical and thermal storage devices: Experimental analysis and simulation of energy management strategies, Applied Energy 137 (2015): 854-866.

[17] D. Setlhaolo, and X. Xia, Optimal scheduling of household appliances with carbon emissions, $1^{\text {st }}$ International Conference on Innovation for Sustainability under climate change and green growth, 26-28 May 2015, Johannesburg, South Africa.

[18] D. Setlhaolo, and X. Xia, Optimal scheduling of household appliances with a battery storage system and coordination, Energy and Buildings 94 (2015): 61-70.

[19] M. Song, K. Alvehag, J. Widen, A. Parisio, Estimating the impacts of demand response by simulating household behaviours under price and $\mathrm{CO}_{2}$ signals, Electric Power Systems Research 111 (2014) 103-114.

[20] N. Zhang, Z. Hu, D. Dai, S. Dang, M. Yao, and Y. Zhou, Unit Commitment Model in Smart Grid Environment Considering Carbon Emissions Trading, IEEE Transaction on Smart Grid, In press.

[21] O. A. Shaneb, G. Coates, and P. C. Taylor, Sizing of residential ?CHP systems, Energy and Buildings 43.8 (2011): 1991-2001.

[22] Ren, Hongbo, Weijun Gao, and Yingjun Ruan, Optimal sizing for residential CHP system, Applied Thermal Engineering 28.5 (2008): 514-523. 
[23] M. De Paepe, P. D'Herdt, and D. Mertens, Micro-CHP systems for residential applications, Energy conversion and management 47.18 (2006): 3435-3446.

[24] J. Harrison, Micro Combined Heat \& Power, Micro Energy Systems: Review of Technology, Issues of Scale and Integration (2004): 77-98.

[25] A. Sheikhi,A. M. Ranjbar, F. Safe, and M. Mahmoodi, CHP optimized selection methodology for an energy hub system, Environment and Electrical Engineering (EEEIC), 10th IEEE International Conference 2011.

[26] M. Houwing, R. R. Negenborn, and B. De Schutter, Demand response with micro-CHP systems, Proceedings of the IEEE 99.1 (2011): 200-213.

[27] A. Sheikhi, A. M. Ranjbar, and H. Oraee, Financial analysis and optimal size and operation for a multicarrier energy system, Energy and Buildings 48 (2012): 71-78.

[28] H. Ren, and W. Gao, Economic and environmental evaluation of micro CHP systems with different operating modes for residential buildings in Japan, Energy and Buildings 42.6 (2010): 853-861.

[29] M. Geidl, and G. Andersson, Optimal power flow of multiple energy carriers, Power Systems, IEEE Transactions on 22.1 (2007): 145-155.

[30] F. Brahman, M. Honarmand, and S. Jadi, Optimal electrical and thermal energy management of a residential energy hub, integrating demand response and energy storage system, Energy and Buildings 90 (2015): 65-75.

[31] S. M. Sichilalu, X. Xia, Optimal energy control of grid tied pv-diesel-battery hybrid system powering heat pump water heater, Solar Energy 115 (2015) 243-254.

[32] H. Tazvinga, B. Zhu, and X. Xia, Energy dispatch strategy for a photovoltaic-winddiesel-battery hybrid power system, Solar Energy 108 (2014): 412-420.

[33] M. Kim, M. S. Kim, J. D. Chung, Transient thermal behavior of a water heater system driven by a heat pump, International Journal of Refrigeration 27 (4) (2004) 415-421.

[34] J. Zhang, X. Xia, Best switching time of hot water cylinder-switched optimal control approach, in: AFRICON 2007, IEEE, 2007, pp. 1-7.

[35] K. Khan, M. Rasul, M. M. K. Khan, Energy conservation in buildings: Cogeneration and cogeneration coupled with thermal energy storage, Applied Energy 77 (1) (2004) $15-34$.

[36] M. Gustafson, J. Baylor, G. Epstein, Direct water heater load control-estimating program effectiveness using an engineering model, Power Systems, IEEE Transactions on 8 (1) (1993) 137-143. 
[37] P. Dolan, M. Nehrir, V. Gerez, Development of a monte carlo based aggregate model for residential electric water heater loads, Electric Power Systems Research 36 (1) (1996) 29-35.

[38] J. Ji, G. Pei, T.-t. Chow, W. He, A. Zhang, J. Dong, H. Yi, Performance of multifunctional domestic heat-pump system, Applied Energy 80 (3) (2005)

[39] Verbruggen, Aviel, et al. "The impact of CHP generation on CO 2 emissions." Energy Policy 20.12 (1992): 1207-1214.

[40] Ren, Hongbo, and Weijun Gao. "Economic and environmental evaluation of micro CHP systems with different operating modes for residential buildings in Japan.” Energy and Buildings 42.6 (2010): 853-861.

[41] S. Sichilalu, T. Mathaba, X. Xia, Optimal control of a wind-pv-hybrid powered heat pump water heater, Applied Energy (2015), In press, Corrected proof. doi:http: //dx.doi.org/10.1016/j.apenergy.2015.10.072. 